$$
\text { MAO - PR - } 92-01
$$

\title{
Factors Which Affect Fatigue Strength of Fasteners
}

\author{
G. W. Skochkol \\ T. P. Herrmann ${ }^{2}$ \\ General Electric Co., Schenectady, New York \\ November 1992
}

\section{ABSTRACT:}

Axial load cycling fatigue tests of threaded fasteners are useful in determining fastener fatigue failure or design properties. By using appropriate design factors between the failure and design fatigue strengths, such tests are used to establish fatigue failure and design parameters of fasteners for axial and bending cyclic load conditions. This paper reviews the factors which influence the fatigue strength of low Alloy steel threaded fasteners, identifies those most significant to fatigue strength, and provides design guidelines based on the direct evaluation of fatigue tests of threaded fasteners. Influences on fatigue strength of thread manufacturing process (machining and rolling of threads), effect of fastener membrane and bending stresses, thread root radii, fastener sizes, fastener tensile strength, stress relaxation, mean stress, and test temperature are discussed.

\section{INTRODUCTION:}

Snow and Langer (Ref. 1) evaluated threaded fastener test data and proposed a fatigue design curve for low Alloy fasteners. The proposal was based upon $K_{f}=4$, and an unnotched fatigue failure curve for low alloy steel adjusted for maximum effect of mean stress using cubic correction for mean stress. Design factors of 1.5 on stress and 5.7 on cycles were used to account for significant crack initiation. That evaluation was followed by Fritz (Ref. 2) who summarized and evaluated 198 full size stud fatigue data on low Alloy steel fasteners and proposed using a zero mean stress design fatigue curve, accounting for the effects of mean stress with cubic correction and using a high temperature correction multiplier. The data summarized by Fritz are re-evaluated here with the objective of separating the variables into those which significantly affect fatigue strength and those which

: GW Skochko, Senior Engineer, General Electric Company, Schenectady, New York.

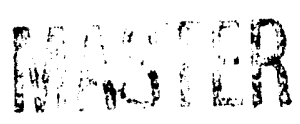

2 TP Hermann, Manager, Mechanical Analysis, General Electric Company, Schenectady, New York. 
are of lesser significance, and thus could be neglected when establishing fatigue design properties of such fasteners.

\section{SUMMARY:}

This paper presents a means of evaluating significant variables which affect the fatigue strength of Low alloy steel fasteners. The data are first segregated into the machined thread, rolled thread and rolled head fillet populations. By utilizing the derived least squares fits of each data population, all data can be adjusted either to the machined or to the rolled thread data base lines, reducing the data scatter and allowing effects of significant variables to be quantified. The most significant factors in fatigue of evaluated fasteners are thread manufacturing process and mean stress effects.

\section{THE DATA BASE:}

References 1 and 2 summarized the low Alloy steel threaded fastener data. That test data population consist of 198 fastener fatigue tests, shown plotted here in Figure 1, with 69 machined and/or ground fasteners, 79 rolled head fasteners, 50 rolled thread fasteners. 12 tests were run at $500^{\circ} \mathrm{F}$ and the remaining 186 tested at $70{ }^{\circ} \mathrm{F}$. The data are summarized below.

\begin{tabular}{|l|c|c|c|c|c|c|}
\hline & Rolled & Machined & Ground & $\begin{array}{c}\text { Machined \& } \\
\text { Ground }\end{array}$ & $\begin{array}{c}\text { Machined \& } \\
\text { Ground \& } \\
\text { Polished }\end{array}$ & $\begin{array}{r}\text { Total } \\
\text { Tests }\end{array}$ \\
\hline Threads Failed & 50 & 2 & 44 & 13 & 4 & 113 \\
\hline Threads Runouts & & 1 & 0 & 0 & 0 & 1 \\
\hline Bolt Heads Failed & 62 & & 5 & & & 67 \\
\hline $\begin{array}{l}\text { Bolt Heads } \\
\text { Runouts }\end{array}$ & 17 & & & & & 17 \\
\hline \hline TOTALS & 129 & 3 & 49 & 13 & 4 & 198 \\
\hline
\end{tabular}

The bolts which failed in threads have been treated as thread failures. Of the 186 fatigue tests at $70^{\circ} \mathrm{F}, 67$ bolts failed in bolt head fillets. with 5 failures in machined head fillets and 62 bolt head failures in rolled head fillets. Although rolled bolt head fillet failures differ from thread failures, it is shown that these failures are comparable in 
fatigue strength to rolled thread failures. The thread data population contains 17 bolt head runouts and 1 machined thread runout. Of the $500^{\circ} \mathrm{F}$ tests, 3 failed in machined threads and 9 failed in rolled threads.

The reported tensile ultimate and yield strengths of fastener materials fell into the following ranges:

\begin{tabular}{|c|c|c|c|c|c|c|}
\hline \multirow[t]{2}{*}{$\begin{array}{l}T \text { test } \\
\text { q }\end{array}$} & \multicolumn{2}{|c|}{$\underset{\mathrm{ksi}}{S_{\text {u range }}}$} & \multicolumn{2}{|c|}{$\underset{\mathrm{ksi}}{S_{y} \text { range }}$} & \multirow[t]{2}{*}{$\underset{\mathrm{ksi}}{\mathrm{S}_{\mathrm{uve}}}$} & \multirow[t]{2}{*}{ 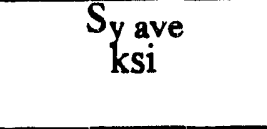 } \\
\hline & $\overline{\operatorname{Max}}$ & $\overline{\text { Min }}$ & $\operatorname{Max}$ & $\overline{\text { Min }}$ & & \\
\hline 70 & 170 & 128 & 164 & 106 & $149(1 \pm 0.14)$ & $135(1 \pm 0.16)$ \\
\hline 500 & 166 & 130 & 147 & 106 & $148(1 \pm 0.12)$ & $126.5(1 \pm 0.16)$ \\
\hline
\end{tabular}

Fatigue tests were conducted at constant load control with a dimensionless maximum nominal stresses $S_{\max } / S_{\mathrm{u}}$ equal to $0.341 \leq S_{\max } / S_{u} \leq 0.724$ for machined threads and $0.248 \leq S_{\max } / S_{u} \leq 0.822$ for rolled threads and head fillets. Failure cycles, at complete separation, ranged between 3285 and 487000 .

The tests of the data base include the following variables which need to be assessed as to their significance to allow meaningful evaluation of the fatigue data.

- studs or bolts

- rolled or machined threads

- different mean stresses

- tests at $70^{\circ} \mathrm{F}$ and at $500^{\circ} \mathrm{F}$

- thread root radii and bolt head fillets radii

- runouts

- fastener diameter ( $1^{\text {" }}$ to $\left.51 / 16^{\prime \prime}\right)$

- fasteners of different ultimate and yield strengths

- tapers

- modulus

- relaxation 
The machined data alone constitute only a third of the data population. From Figure 3, they are judged insufficient to develop a design fatigue curve in the high cycle regime. To sort the test variables into significant and insignificant variables. we need to use the combined rolled and machined data base.

Together with the variables considered by Snow and Langer, Reference 1, and by Fritz, Reference 2, the following evaluates their impact on fastener fatigue strength. No systematic tests were conducted to segregate each of the variables. They are assessed based on engineering judgement, categorizing them into significant (need to adjust for) and secondary (within scatter band) categories relative to their impact on fatigue strength.

\section{EVALUATION OF VARIABLES WHICH AFFECT FATIGUE STRENGTH:}

This following categorizes test variables into those that are significant and those that are vot.

\section{(a) Fastener Type (Stud or Bolts) and Material Strength}

The test data were segregated according to the location of the fastener failure, thread or bolt head fillet and whether the thread was machined or rolled. Bolts which failed in threads as well as runouts were conservatively treated as failures.

Figure 1 shows a plot of $S_{\text {alt }}$ versus cycles to failure $N_{f}$ for all 198 data, without segregating the data according to fastener type. Figure 2 also shows a plot of $S_{a l t} / S_{u}$ versus cycles to failure $N_{f}$ for the 198 non segregated data, after normalizing the data relative to the reported tensile strength of fastener material. Normalization of nominal alternating stresses by $S_{\mathrm{u}}$ reduces the scatter at low cycles without affecting it at high cycles. Thus, the following uses normalized data to account for fatigue tested stuc's being of different tensile strengths.

Figure 3 shows a plot of the 198 fatigue test data segregated according to the location of the failure i.e. machined thread or rolled thread and bolt head fillet. Figure 3 shows a clear benefit of rolling the thread and bolt head tillets on high cycle fatigue strength compared to machined threads. Also. rolled thread and bolt fillet data fall into a 
relatively narrow scatter band. suggesting little difference in fatigue behavior between rolled thread and rolled bolt head fillets. Therefore, the distinction between rolled bolt head fillets and threads is considered minor compared to the effect of the thread manufacturing process.

Figure 4 compares the least squares fits (LSF's) of the data of Figures 3, and shows that, above 10,000 cycles, the machined threads fall considerably below either the rolled head or of the rolled thread data while rolled head fillets and rolled threads are comparable.

\section{(b) Manufacturing Process, Rolled or Machined Threads:}

The differences in fatigue due so manufacturing process and the location of failures are clearly shown by the least square fits (defined in Table I) of the different data populations, plotted in Figure 4. Figure 4 shows that rolled thread and rolled bolt head fillets are of comparable strength while the machined threads are the most limiting in fatigue. Thread manufacturing process is thus seen to be a significant variable.

Having LSFs of segregated data populations, the test data of any of the fastener types could be adjusted to any other fastener type base line by the ratio of their least squares fits. This offers an opportunity to study the effects of variables such as mean stress, as function of cycles based on a larger population base than could be made if each population were treated separately.

Figure 5 shows all 198 test data adjusted to machined data base line, compared to the least squares fit of the machined thread data from Figure 4. It is shown that the adjusted data scatter bands are reasonably narrow and that the LSF curve of the machined data population is reasonably representative of the adjusted data. We propose to develop a fatigue failure curve only for machined data. Such a curve can then be used conservatively for the rolled threads and for bolt head fillets as well. 


\section{(c) Runouts:}

The thread data population contains 18 runouts, 17 at $70^{\circ} \mathrm{F}$ and 1 at $500^{\circ} \mathrm{F}$. The runouts were conservatively treated as failures at the runout cycles, and are not considered a significant variabie if the runouts fall within the data scatter band.

\section{(d) Mean Stress:}

The fatigue tests have been conducted with $S_{\max } / S_{u}$ ranging between 0.25 and 0.82 . Such large range of $S_{\max } / S_{\mathfrak{u}}$ values suggests that the mean stress could be a significant variable on fatigue strength of fasteners and will be further evaluated in the following.

\section{(e) Test Temperanure:}

Figure 6 shows the 12 high temperature tests adjusted for manufacturing process to the machined data base line compared to least squares fit of the machined data from Figure 4. The few test data at $500^{\circ} \mathrm{F}$ are believed to be insufficient to allow meaningful assessment of high temperature effects on fatigue strength of rolled and of machined threads.

\section{(f) Thread Taper:}

Although tapered threads enhance fatigue strength of fasteners, the data on tapered threads is neither systematic nor accurate enough to quantify the benefits of thread tapers on increase of fatigue strength. The benefits of tapered threads are believed to be dependent on stress amplitude and material, and are most likely of the order of the test data scatter band. Without carefully controlled fatigue tests of tapered threads, the existing data do not permit quantification of this variable. 


\section{(g) Fastener Size:}

Detailed segregation of the test data according to rastener size is not feasible because of the limitations of the available data base. The available data do not allow quantifying size effect because this effect could be masked by other test variables. Although, it could be expected that smaller fasteners are likely to be more fatigue resistant than the larger fasteners, the use of a single failure fatigue curve is more practical than multiple curves based on fastener size. Data in Figure 5 represent fatigue strengths of 1 through 5 inch diameter fasteners and they fall into a reasonably narrow, and well behaved scatter band. Data (not shown) have been segregated into three different fastener size populations to qualitatively differentiate fatigue strength according to fastener size. It was shown that the differences in fatigue strengths of small and of large diameter fasteners are within the scatter band of the test data. Thus, fastener size is of secondary importance, and is of the order of data scatter.

\section{(h) Thread Root Radius or $\mathrm{K}_{\mathrm{t}}$ Factor:}

No systematic, well controlled tests were done examining the effects of thread root radii. The tests in the data base have been made on fasteners with reported root radii of 10 to 21 mils in 1 through 5 inch diameter fasteners. These are prototypical thread root radii. Root radii are commonly accepted as significant for crack initiation but do not affect crack propagation. Although, the investigations in References 1 and 2 attempted to determine fatigue strength reduction factors for machined and rolled threads, the significance of such a narrow range of root radii on fatigue strength of 1 through 5 inch diameter fasteners is perhaps masked by other variables, making root radii of secondary importance, unless root radii are extremely small.

Because root radii are a variable inherent in the nominal stress based fatigue curve being derived here, extrapolations to other than the range of root radii tested must be based on engineering judgment. 


\section{(i) Young's Modulus:}

Young's Modulus is not a significant variable in load controlled fatigue tests of fasteners. The use of Young's Moduli ratio to correct load controlled fatigue data and failure or design fatigue curves for temperature does not appear to be justified.

Test data are needed to show if its use is appropriate for load cycling data.

\section{(j) High Temperature Stress Relaxation:}

High temperature stress relaxation is unlikely to influence the fatigue strength of machined threads. Stress relaxation could be significant in reducing fatigue strength of rolled threads because the high temperature could reduce the beneficial residual stresses in rolled threads which account for their increased fatigue strength. Therefore, high temperature stress relaxation may be a significant variable for rolled threads, especially at higher cycles to failure, if their increased fatigue strength is taken advantage of.

\section{IIL. DERIVATION OF FATIGUE FAILURE CURVES:}

The review of the data in Part II identified the significant variables which could affect the fatigue strength of fasteners. Specifically, thread manufacturing process and mean stress have been identified as being significant variables whose effects need to be quantified. Temperature has also been identified as potentially significant, but data are insufficient to assess the effect.

The following method is used to quantify these significant effects. The nominal alternating stress data, normalized by $S_{u}$, are systematically segregated according to thread manufacturing method and location of fastener failure (bolt head fillet or thread). Then, the ratios of LSF's of the segregated data form cycle dependent adjustment functions for variables. Using these functions, the data can be adjusted either to machined thread, to rolled thread. 
or to bolt head fillet base lines. All data were adjusted to machined thread data base line. The adjusted data are shown in Figure 7 as a function of $S_{\text {mean }} / S_{u}$. Note that data adjustment was made only to $S_{a l t} / S_{u}$ while holding $S_{\text {mean }}$ constant so that the adjustment reflects a change only in the stress range.

From Figure 7, it is observed that data are lacking at mean stress levels above $0.5 \mathrm{~S}_{\mathrm{u}}$. Hence, any conclusions about mean stress effect are limited to the $S_{\text {mean }}$ range below $0.5 \mathrm{~S}_{\mathrm{u}}$.

To examine the effect of $S_{\text {mean }}$, the data of Figures 5 and 7 are grouped by $S_{\text {alt }}$ and cycle ranges. Figure 8 repeats the plot of Figure 5, showing 5 arbitrary cycle ranges for grouping the data. The data within each of these cycle ranges are examined for mean stress effects. At low cycles and high $S_{a l t} / S_{u}$ values, below these ranges, mean stress effects were found either not to exist or to be masked by data scatter. Figures 9 through 13 show that, in a cyclic range frcm 30200 to 48700 cycles, linear least squares fits of the form $S_{a l} / S_{u}=A-B S_{m e a n} / S_{u}$ apply; exception is a LSF at 138300 cycles, which showed nearly no dependence on mean stress. These LSFs indicated a reduction of $S_{\mathrm{alt}} / \mathrm{S}_{\mathrm{u}}$ with increased $\mathrm{S}_{\text {mean }} / \mathrm{S}_{\mathrm{u}}$.

The evaluation of the LSFs in Figures 9 through 13 showed that they intersect the abscissa at approximately $\mathrm{S}_{\max } / \mathrm{S}_{\mathrm{u}}=\mathrm{S}_{\text {mean }} / \mathrm{S}_{\mathrm{u}}=1.54$. Fitting linear LSF's between the coordinates $\mathrm{S}_{\mathrm{alt}} / \mathrm{S}_{\mathrm{u}}$ at $\mathrm{S}_{\text {mean }} / \mathrm{S}_{\mathrm{u}}=0.2$, (given in Figures 9 through 13 ) and $S_{\text {mean }} / S_{u}=S_{\max } / S_{u}=1.54$, allows adjusting the originally computed LSF's to a common intercept $S_{\max } / S_{u}=S_{\text {mean }} / S_{u}=1.54$. These adjusted LSF's were then used to determine the maximum mean stress correction $\left(S_{\max } / S_{u}=0.7\right)$ to be applied to the failure curve shown in Figure 5 . Figure 14 compares the data to the L.SF curve of Figures 5, as well as shows the failure curve which has been adjusted for maximum effect of mean stress, $S_{\max } / S_{u}=0.7$.

The ratio of the original LSF ordinates to those corrected for maximum effect of mean stress is approximately 1.52. Thus, the failure curve for $S_{\max } / S_{u}=0.7$ is defined as $\left.S_{\text {alt }} / S_{u}=(0.04216+21.749 N)-0.535\right) / 1.52 \cong 0.028$ $+14.31 \mathrm{~N}-0.535$. 
The above procedure could be applied to the data adjusted to the rolled thread and bolt head fillet radii base lines. Also, if needed, failure curves for different $S_{\max } / S_{u} \leq 0.7$ could be developed as an alternative to a single, maximum mean stress effect adjustment.

\section{CONCLUSIONS:}

1. Data evaluations have shown that by segregating the data, the effects of thread manufacturing can be quantified. By adjusting the data for these effects, 198 data were examined for effects of mean stress. Least squares fits of data showed mean stress dependence, however tests with high mean stresses, at $S_{\max } / S_{u}$ are needed to confirm predictions made from tests at lower mean stresses and to quantify mean stress effects.

2. Fastener strength is not a significant variable on fatigue strength, and that the derived fatigue failure curve adequately accounts for size effect. Evaluation of these issues showed the following:

(a). Inclusion of rolled data in the evaluation did not bias the derived failure curve for machined threads unconservatively upwards.

(b). For AISI 4340 steel fasteners, tensile strength of fastener material is not a significant variable which could influence the fatigue strength of fasteners.

(c). For the machined thread fasteners of 1 inch to $51 / 16$ inch diameter, size effect is not a significant variable.

3. A single, nominal stress based fatigue failure curve for $70^{\circ} \mathrm{F}$ was determined for AISI 4340 steel machined threaded fasteners. This curve incorporated a correction for maximum effect of mean stress.

4. The procedure used to develop the failure curve for machined threads could also be used to develop similar failure curves for rolled thread fasteners as well as for fatigue evaluation of rolled bolt head fillets. 
5. Test data at $500^{\circ} \mathrm{F}$ are insufficient to provide corrections needed to account for high temperature. Data at high temperatures are needed to quantify adjustments to fatigue evaluations which account for high temperatures.

6. A fatigue failure curve such as developed in Figure 14, if properly adjusted downward, could be used to predict crack initiation in threaded fasteners for start of crack growth calculations, or with appropriate design factors, it could be used for fatigue design of fasteners.

\section{NOMENCLATURE:}

$A_{s}=\quad$ tensile area of fastener thread $=0.7854(D-0.9743 / n)^{2}$, inches ${ }^{2}$.

$\mathrm{D}=\quad$ Basic major thread diameter, inches.

$\mathrm{n}=\quad$ threads per inch.

$\mathrm{N}_{\mathrm{f}}=\quad$ cycles to failure.

$S_{\mathrm{a}}=\mathrm{S}_{\mathrm{alt}}=$ nominal alternating stress on tensile area of thread $\left(\mathrm{A}_{\mathrm{s}}\right)$, exclusive of stress concentration factors, ksi.

$S_{\text {mean }}=\quad$ nominal mean stress on tensile area of fastener thread, $\left(A_{s}\right)$, exclusive of stress concentration factors, ksi.

$S_{\max }=\quad$ nominal maximum stress on tensile area of fastener thread $\left(A_{s}\right)$, exclusive of stress concentration factor, ksi.

$S_{\mathrm{u}}=\quad$ ultimate tensile strength, $\mathrm{ksi}$.

\section{REFERENCES:}

1. ASME Paper 66-Pet-8, Low Cycle Fatigue of Large Diameter Bolts, A. L. Snow and B. F. Langer, September, 1966, 8 pp.

2. ASME Paper 67-Met-23, Cyclic Stress Limits For Bolts and Studs, by R. J. Fritz, Published by ASME April 1967, 23 pp. 


\section{TABLE I. \\ LEAST SQUARE FITS OF DATA POPULATIONS}

The following least squares fits of AISI 4140 and AISI 4340 load controlled fastener fatigue test data obtained by using program ENPLOT:

(1). Machined Thread Data:

$$
\mathrm{S}_{\mathrm{a}} / \mathrm{S}_{\mathrm{u}} @ 70^{\circ} \mathrm{F}=0.04216+21.749 * \mathrm{~N}_{\mathrm{f}}^{-0.535}
$$

(2). Rolled Thread Data :

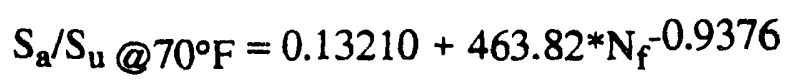

(3). Rolled Bolt Head Fillet Radii:

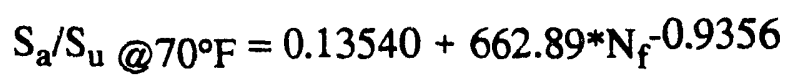




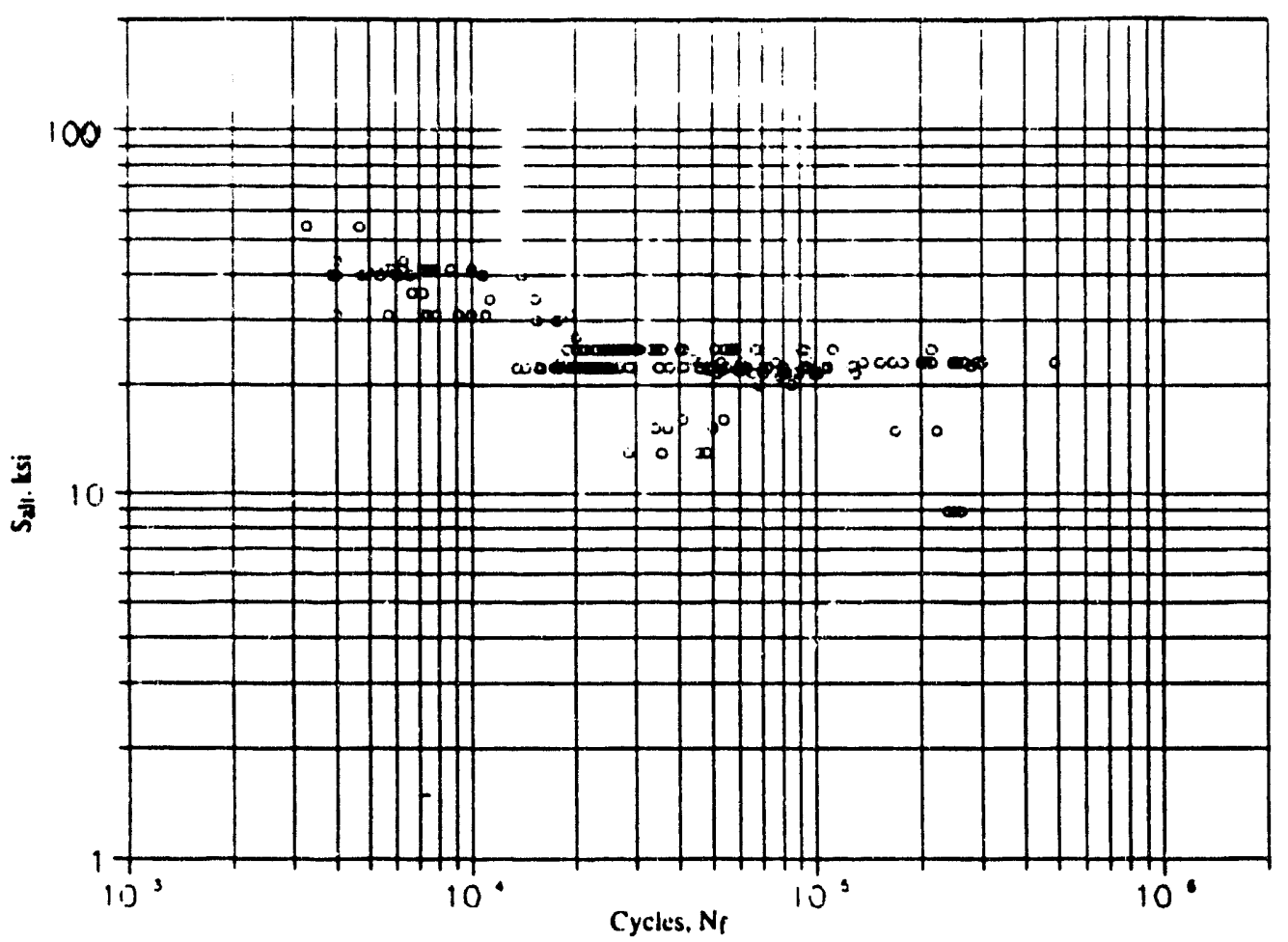

FIGURE 1. S औ VERSUS CYCLES NiPLOT for MACHINED and ROI.L.ED THREADS and ROLLED

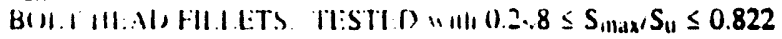

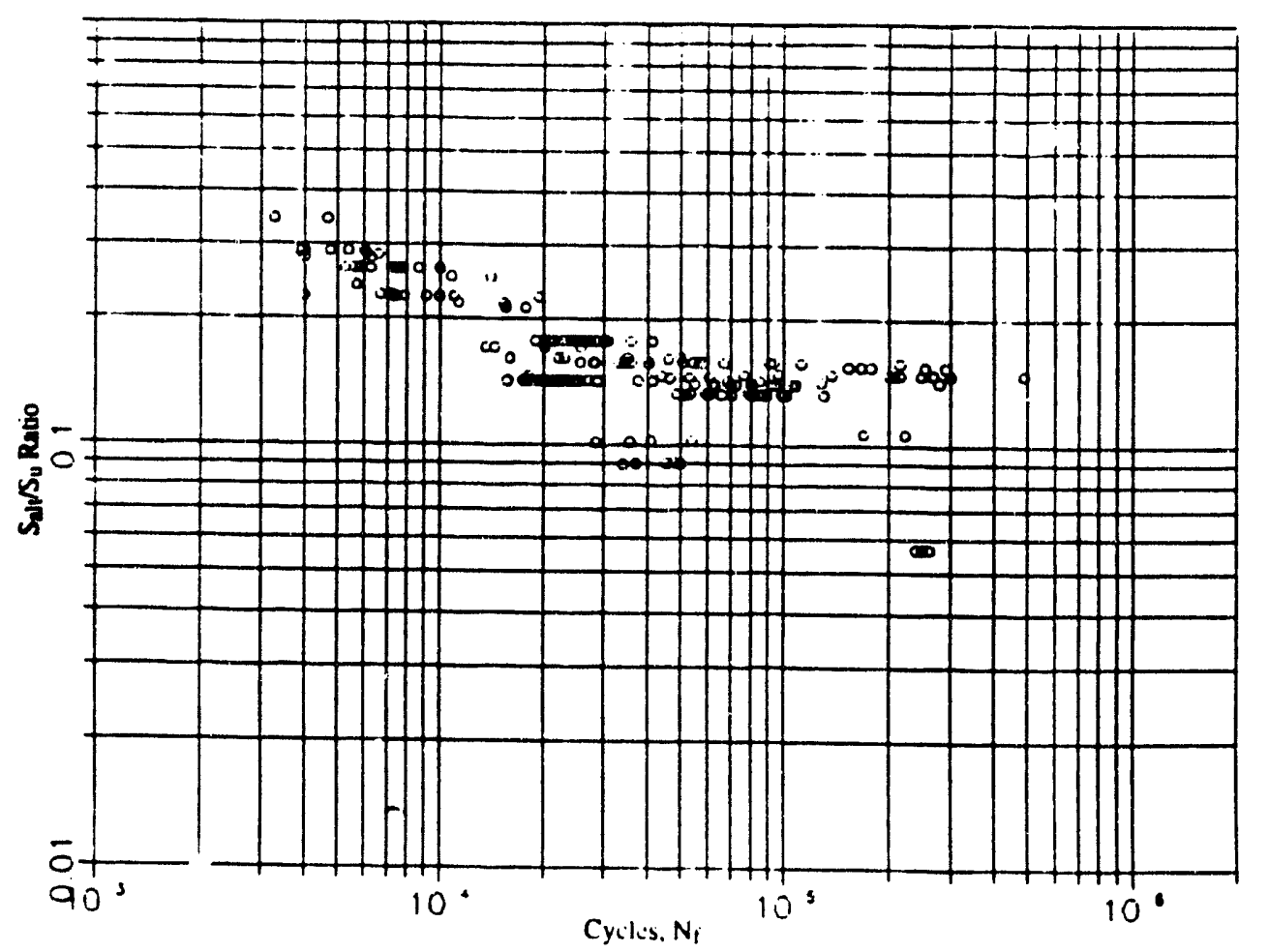

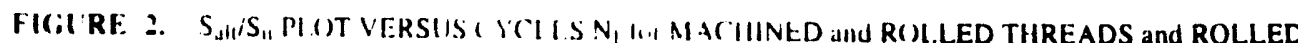

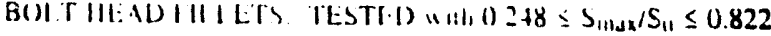




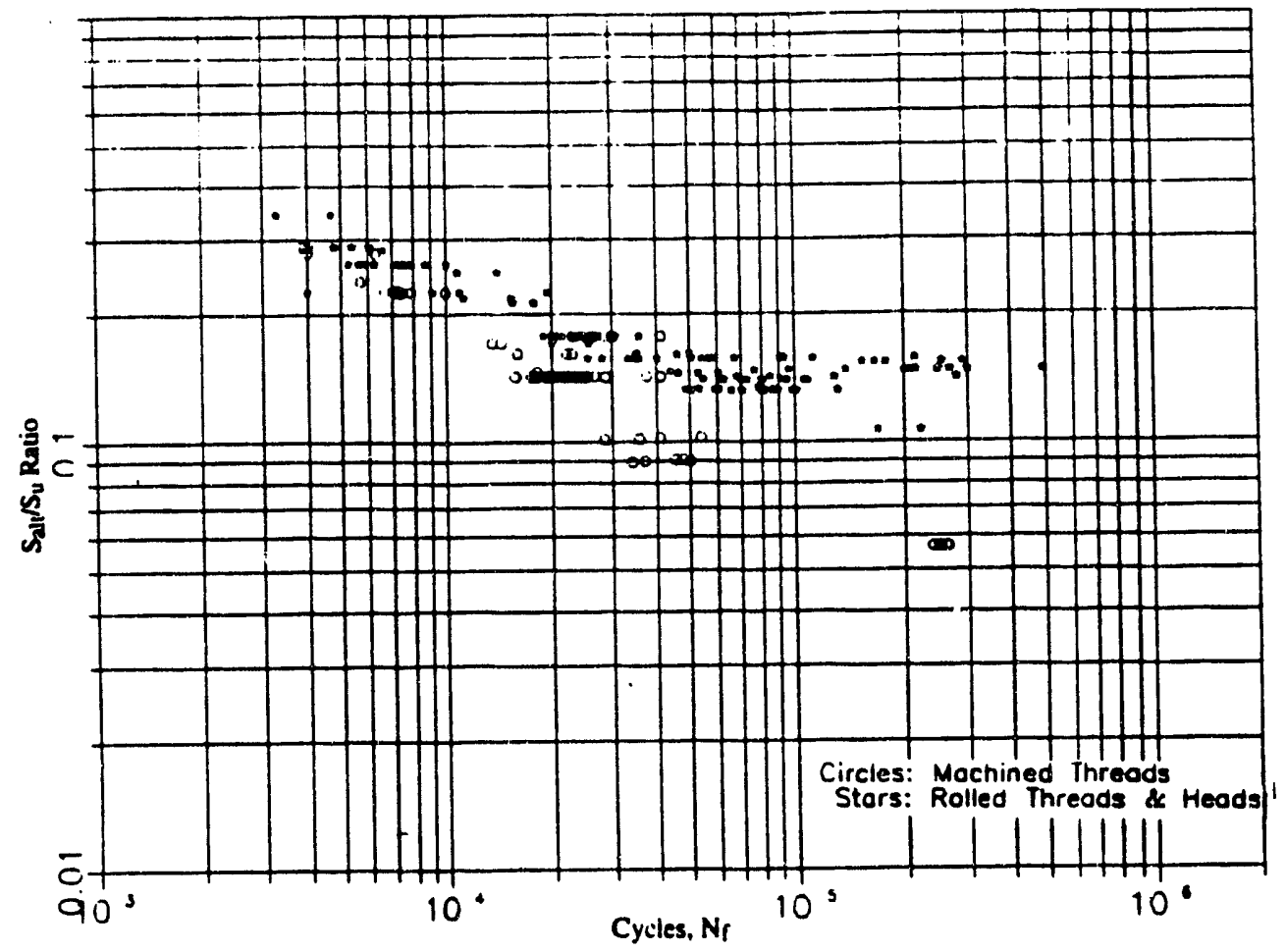

FIGURE 3. PLOT of $S_{\mathrm{ih}} / S_{\mathrm{U}}$ VERSUS CYCLES $N_{1}$ : MACHINED THREADS VS. ROLL ED THREADS and BOIIT HEAD FII LETS. TESTED will $0.2+8 \leq S_{\text {max }} / S_{11} \leq 0.822$

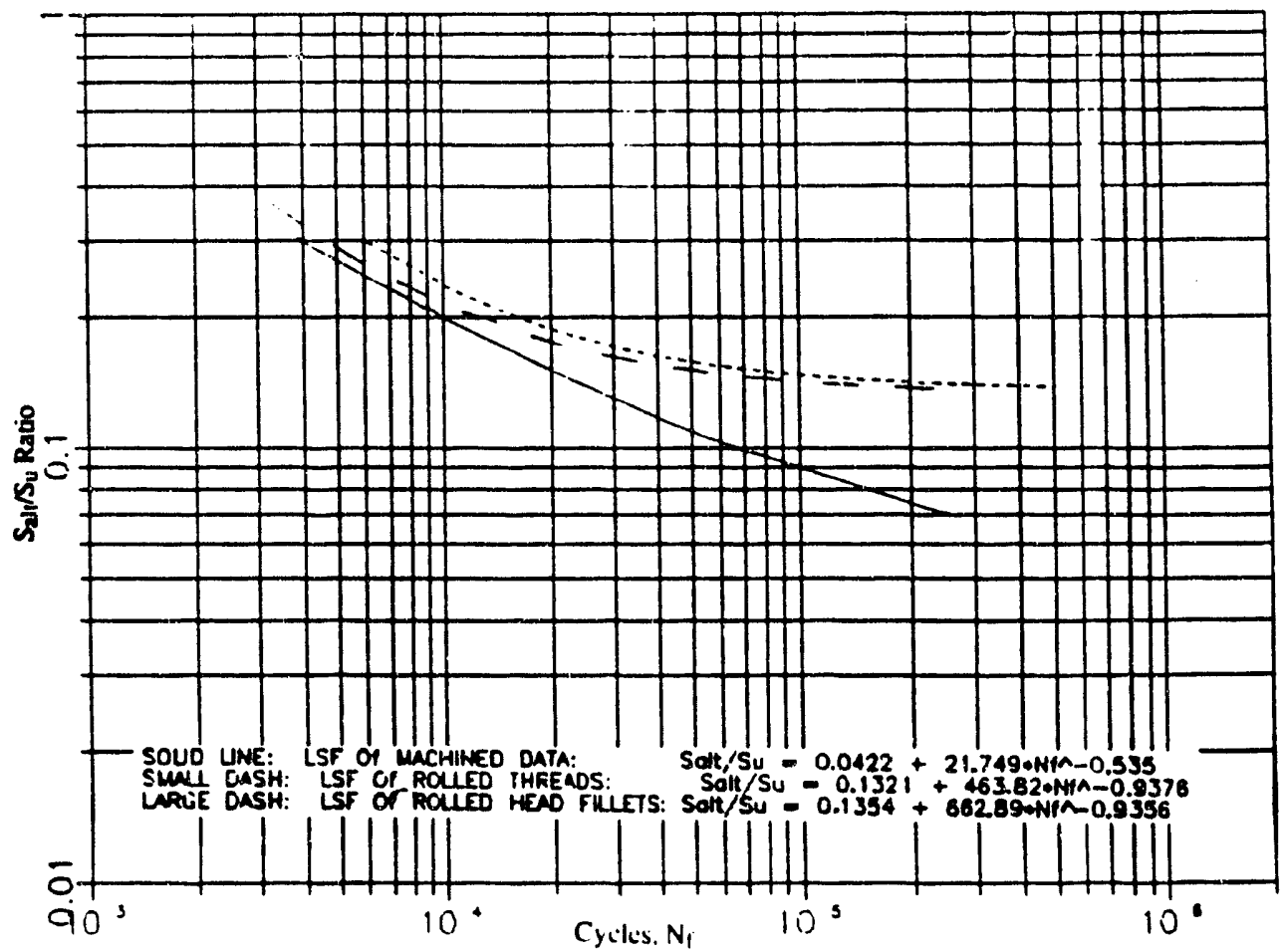

FIGURE +. LEA ST S(OUARES FITS IF $S_{\text {, }}$ /S, VI:RSIIS CICI ES N, FOR MACHINED and ROLLED

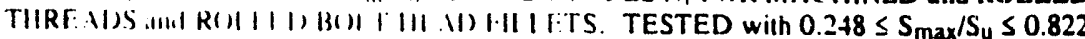




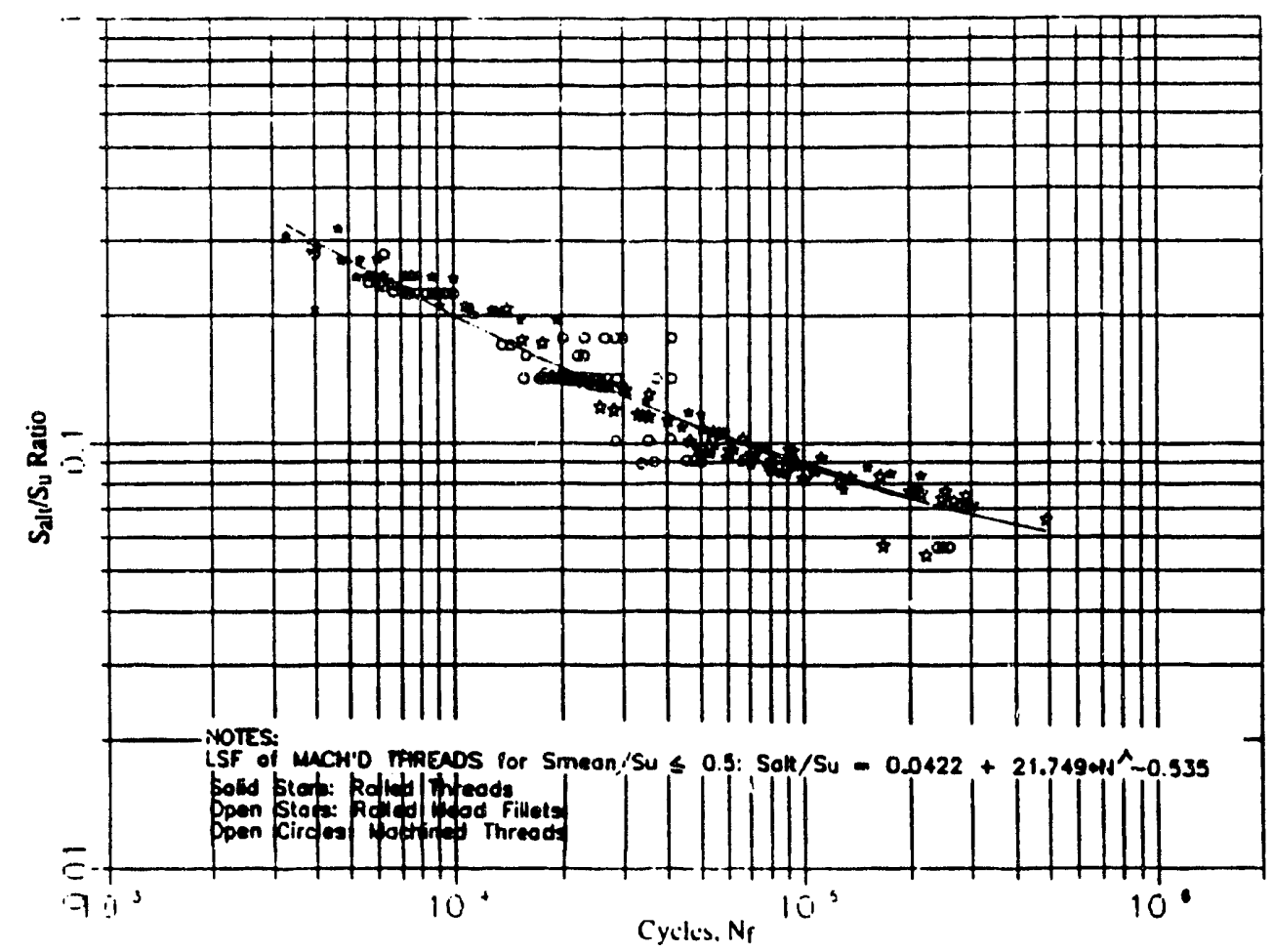

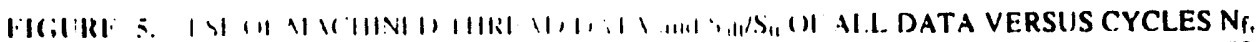

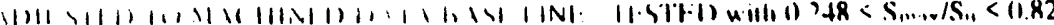

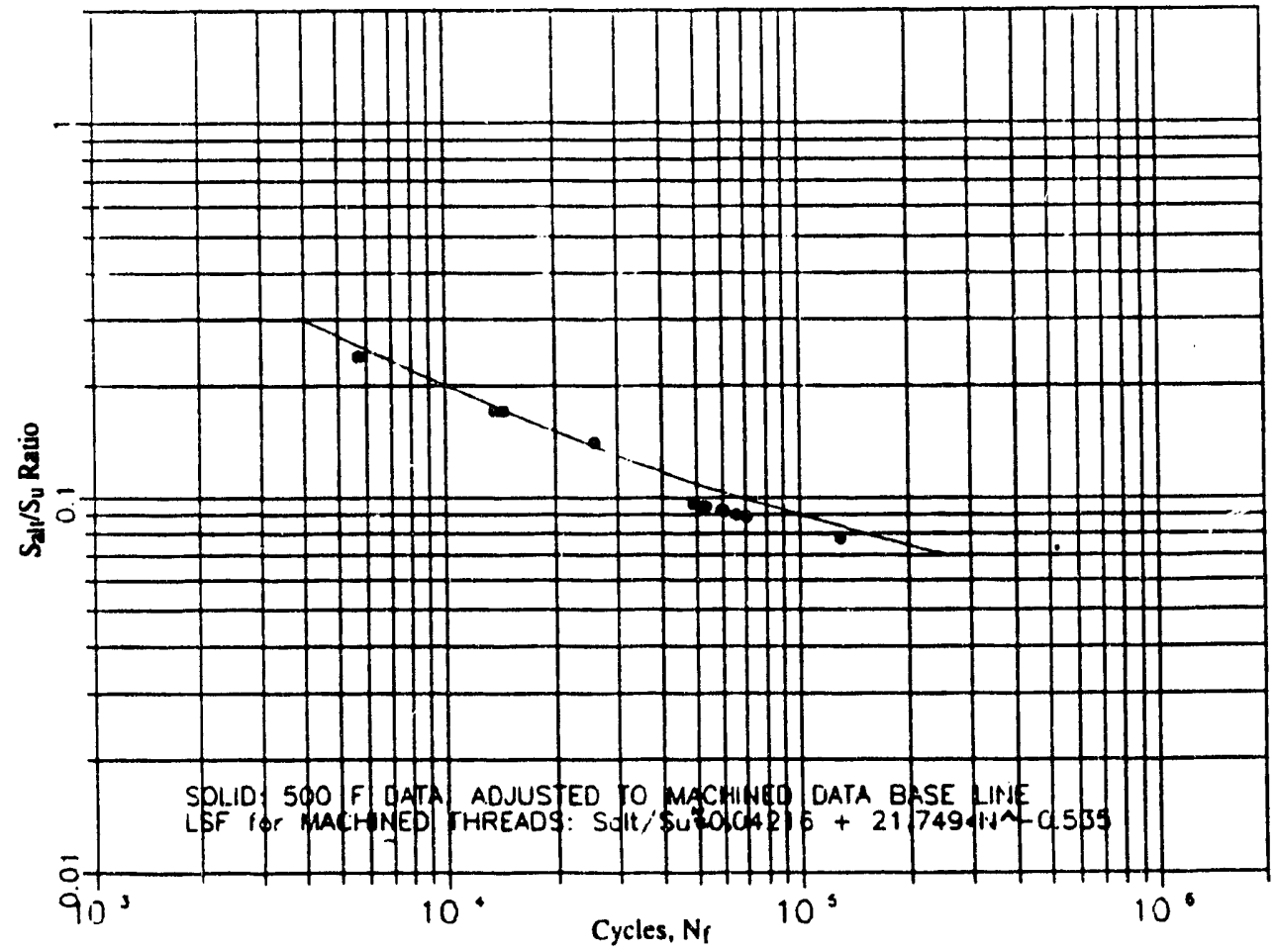

FICURE 6. LSF, OI MACHINED DATA C(UMPARED TU S(X) F DATA ADJUSTED TO MACHINED DATA BASE I.INE 


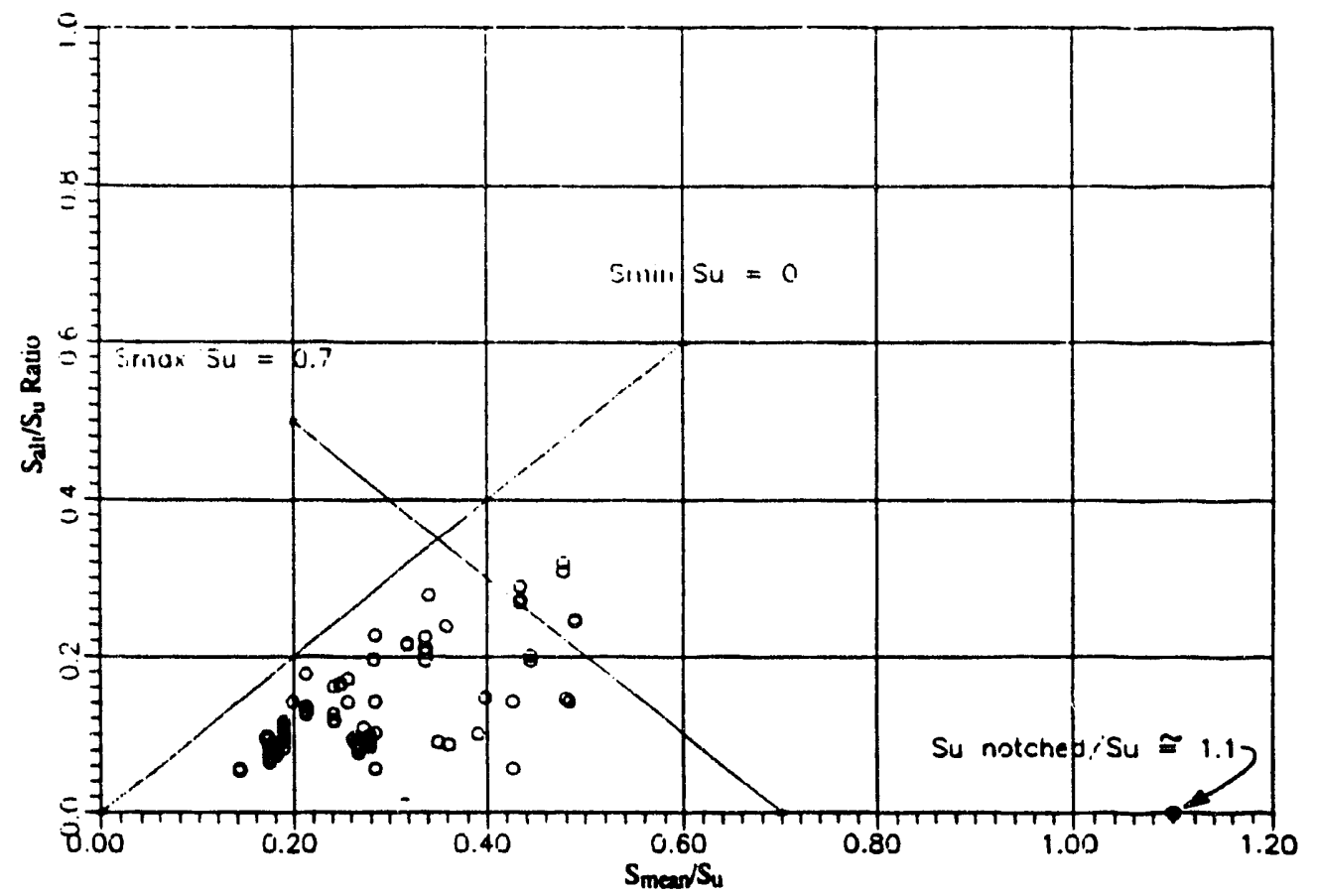

FIGURE 7. PLOT OF $S_{\text {all }} / S_{\text {t1 }}$ DATA VERSUS $S_{\text {"II }} / S_{11} F() R$ AI.L. DATA ADJUSTED TO MACHINED DATA BASE LINE, F()R $0.2+8: S_{\max } / S_{11} \leq 0.820$

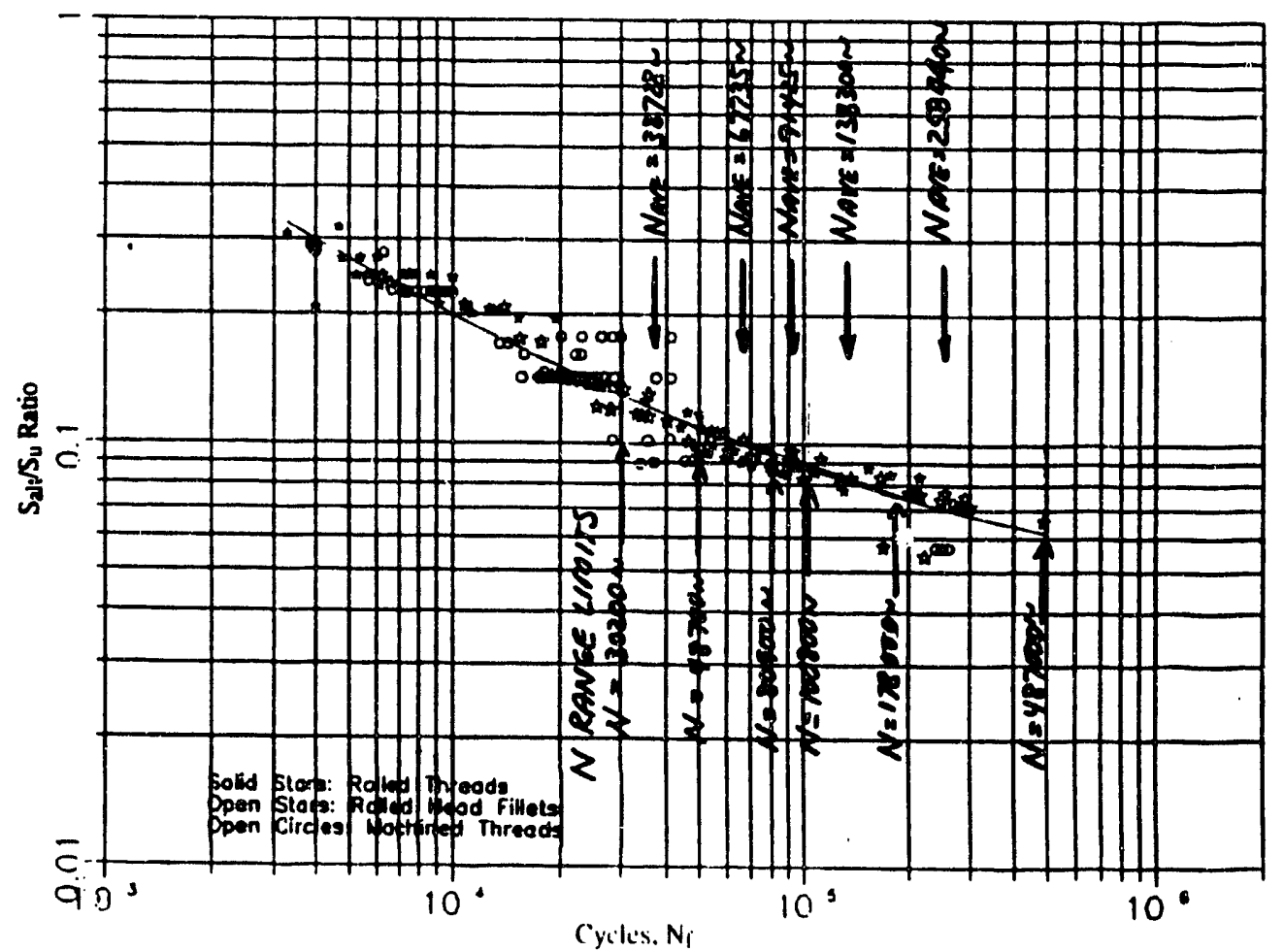

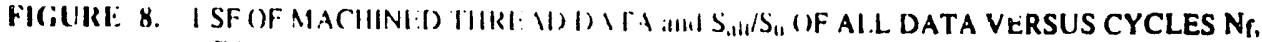

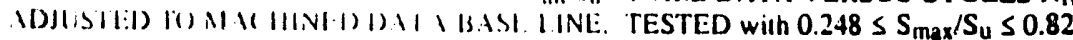




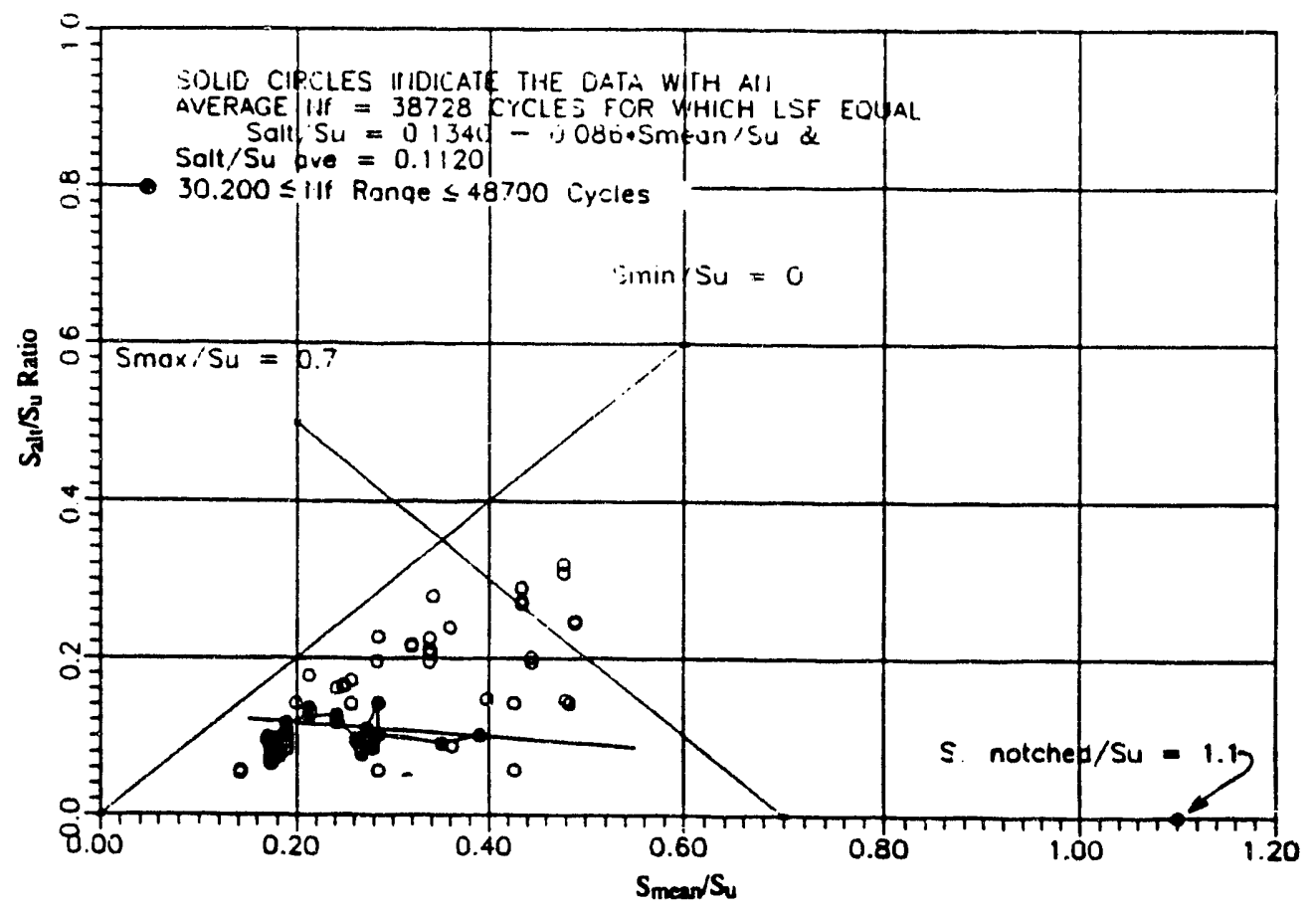

FIGURE 9. PLOT OF $S_{\text {all }} / S_{u}$ DATA VERSUS $S_{\text {IIEau }} / S_{11}$ F()R ALL DATA ADJUSTED TO MACHINED DATA BASE I.INE. FOR (I. $2+8 \leq S_{\max } / S_{11} \leq 0.820$

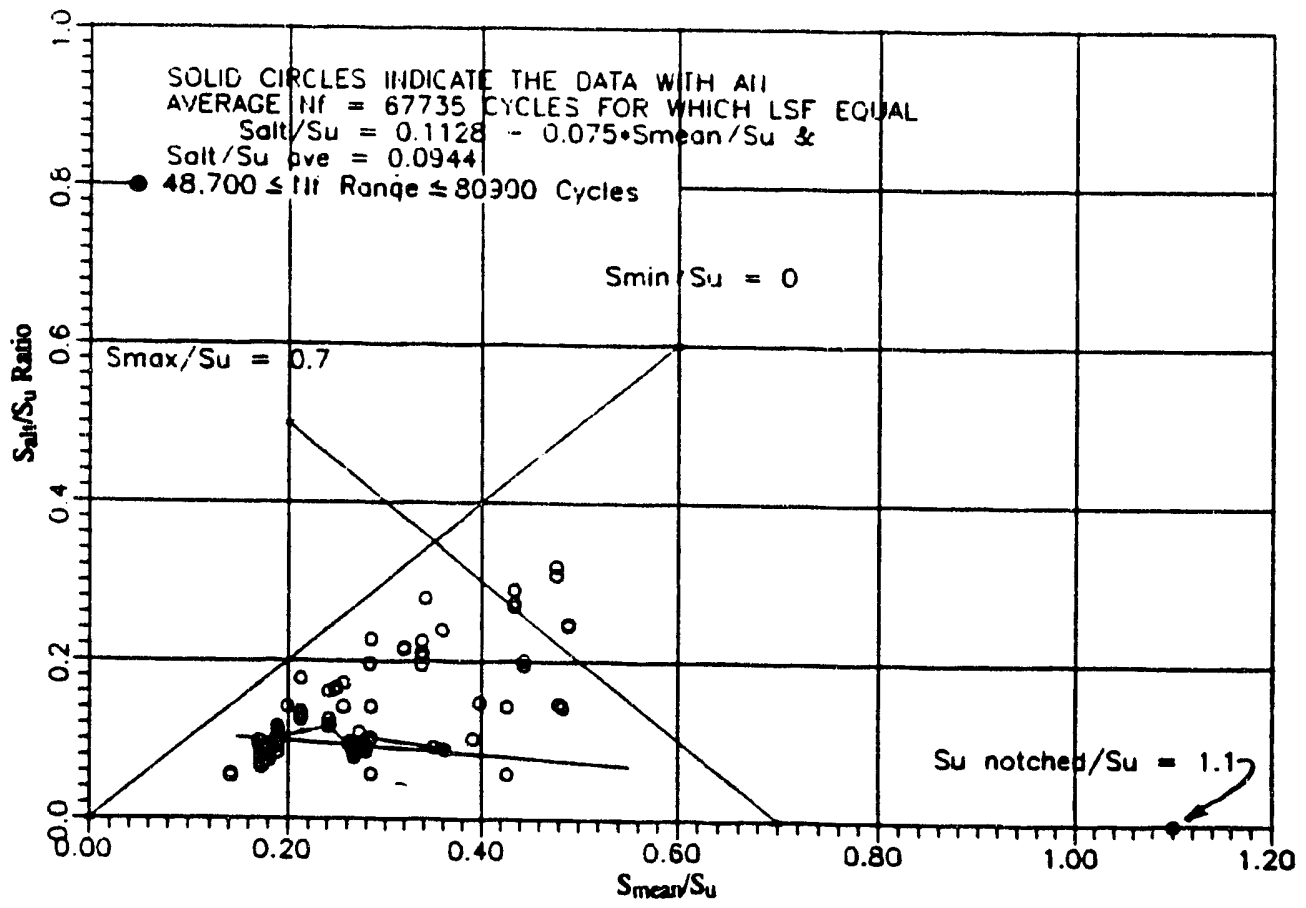

FIGURE 10. PLOT OF $S_{\text {all }} / S_{11}$ DATA VIRSUIS $S_{111}$ III $S_{11}$ FIIR AI.I. DATA ADJUSTED TO MACHINED DATA BASE IINE. IOR II $\leq+8: S_{\operatorname{miax}} / S_{11} \leq 0.820$ 


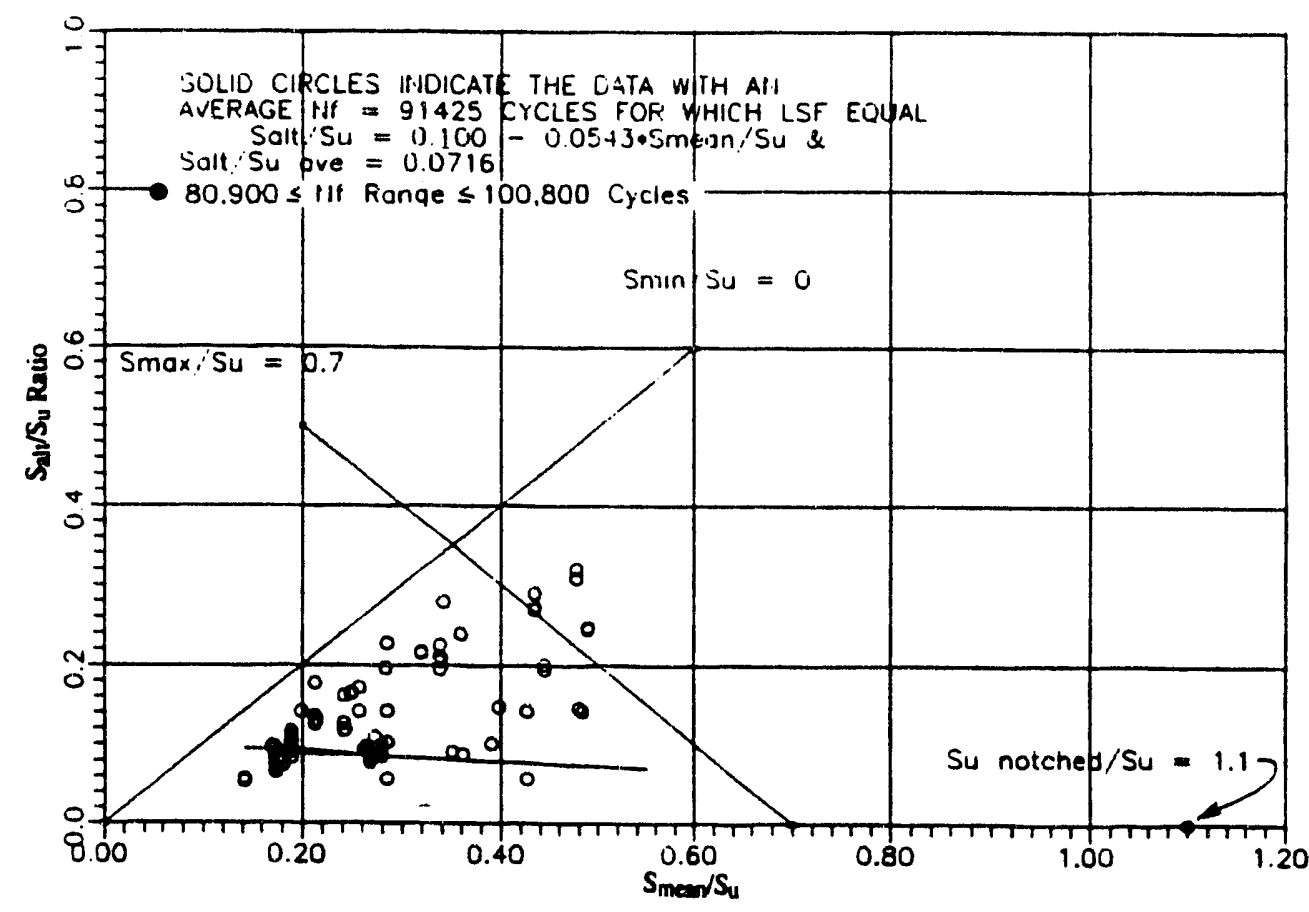

FIGURE 11. PLOT OF $S_{2 \mid l} / S_{u}$ DATA VERSUS $S_{\text {Inwinn }} / S_{11} F($ R ALL DATA ADJUSTED TO MACHINED DATA BASE LINE. F()R $0.248 \leq S_{\max } / S_{u} \leq 0.820$

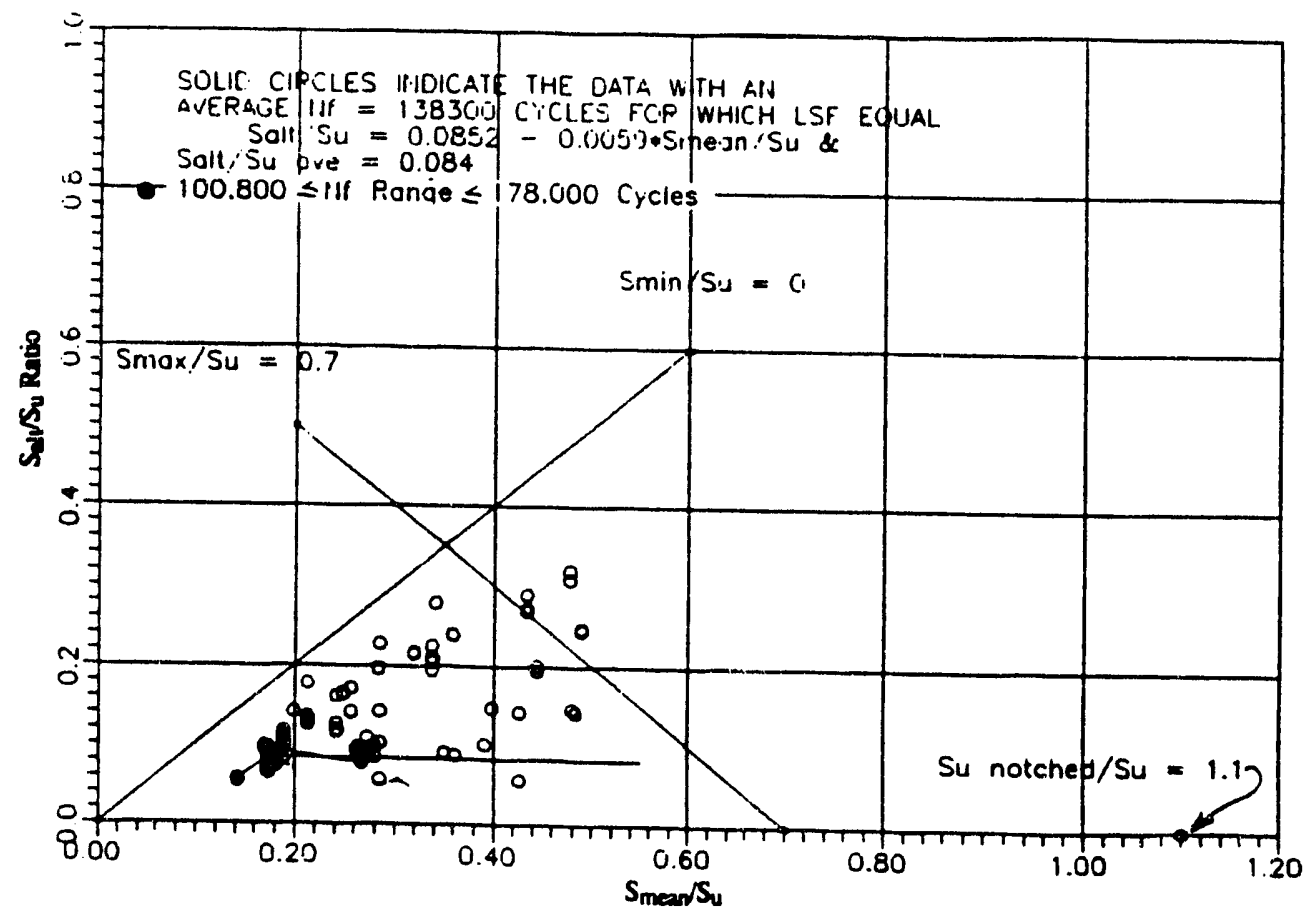

FIGURE 12. PLOT OF $S_{2 l} / S_{u}$ DATA VERSUS $S_{\text {mean }} / S_{u}$ FOR ALL DATA ADJUSTED TO MACHINED DATA BASE LINE. FOR $0.248 \leq S_{\max } / S_{u} \leq 0.820$ 


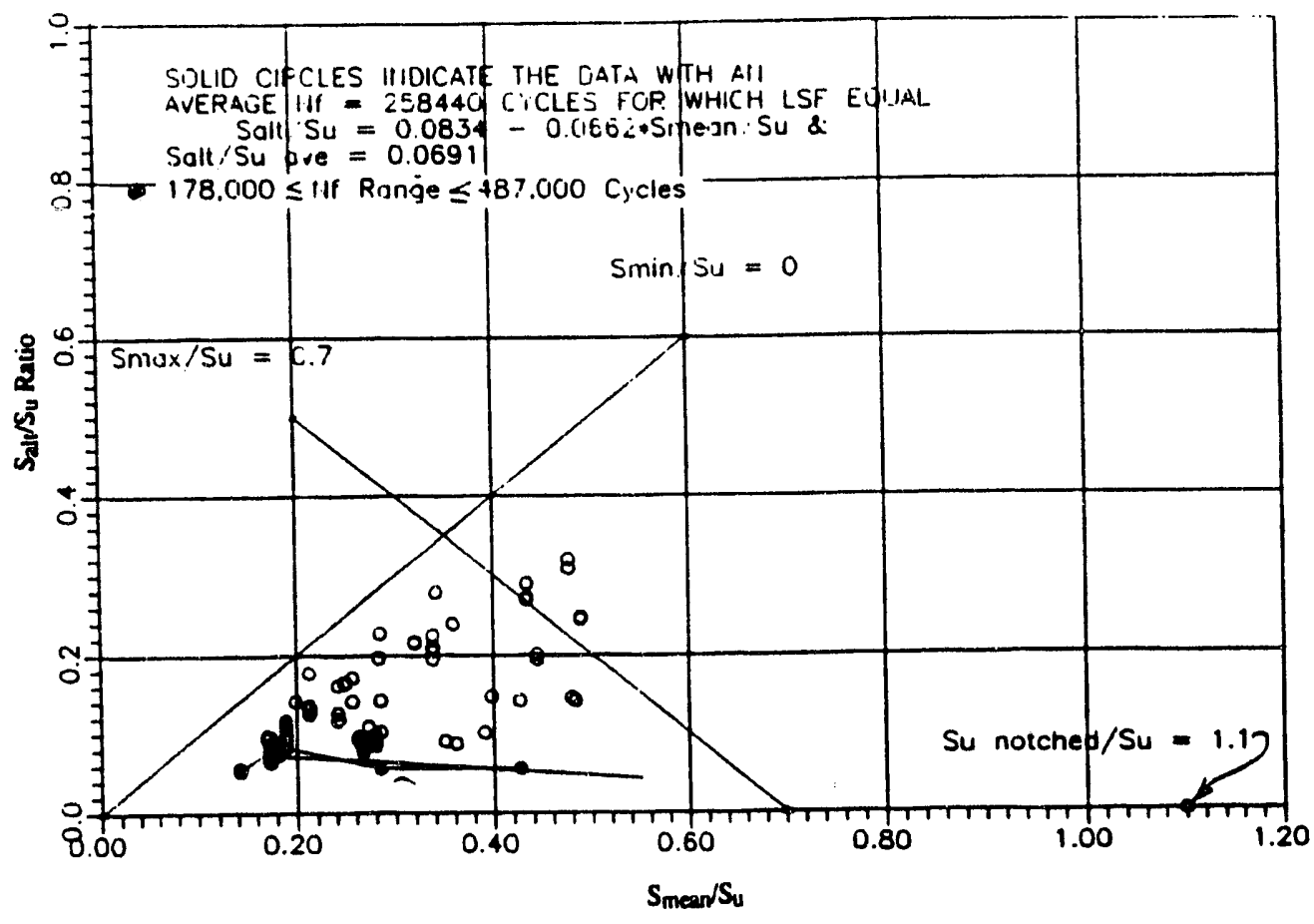

FIGURE 13. PLOT OF $S_{2 \mathrm{l}} / S_{\mathrm{u}}$ DATA VERSUS $S_{\text {mear }} / S_{\mathrm{u}}$ FOR ALL DATA ADJUSTED TO MACHINED DATA BASE LINE. FOR $0.248 \leq S_{111 a x} / S_{11} \leq 0.820$

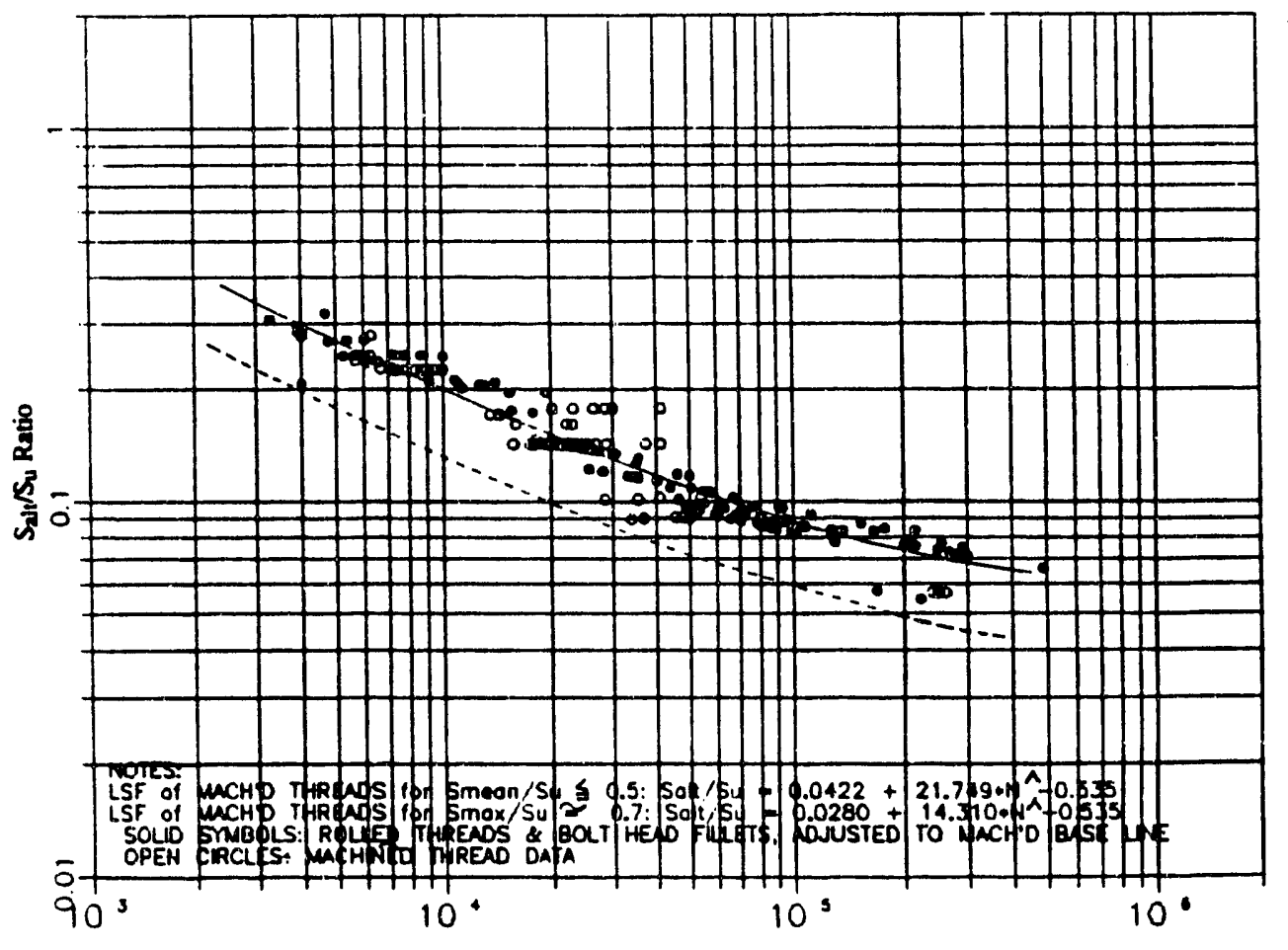

Cycles, $\mathrm{N}_{\mathbf{f}}$

FIGURE 14. LSF FOR $S_{\text {mean }} / S_{11} \leq 0.5$ and FOR $S_{111 a x} / S_{11} \approx 0.7$, and DATA ADJUSTED TO MACHINED DATA BASE LINE 

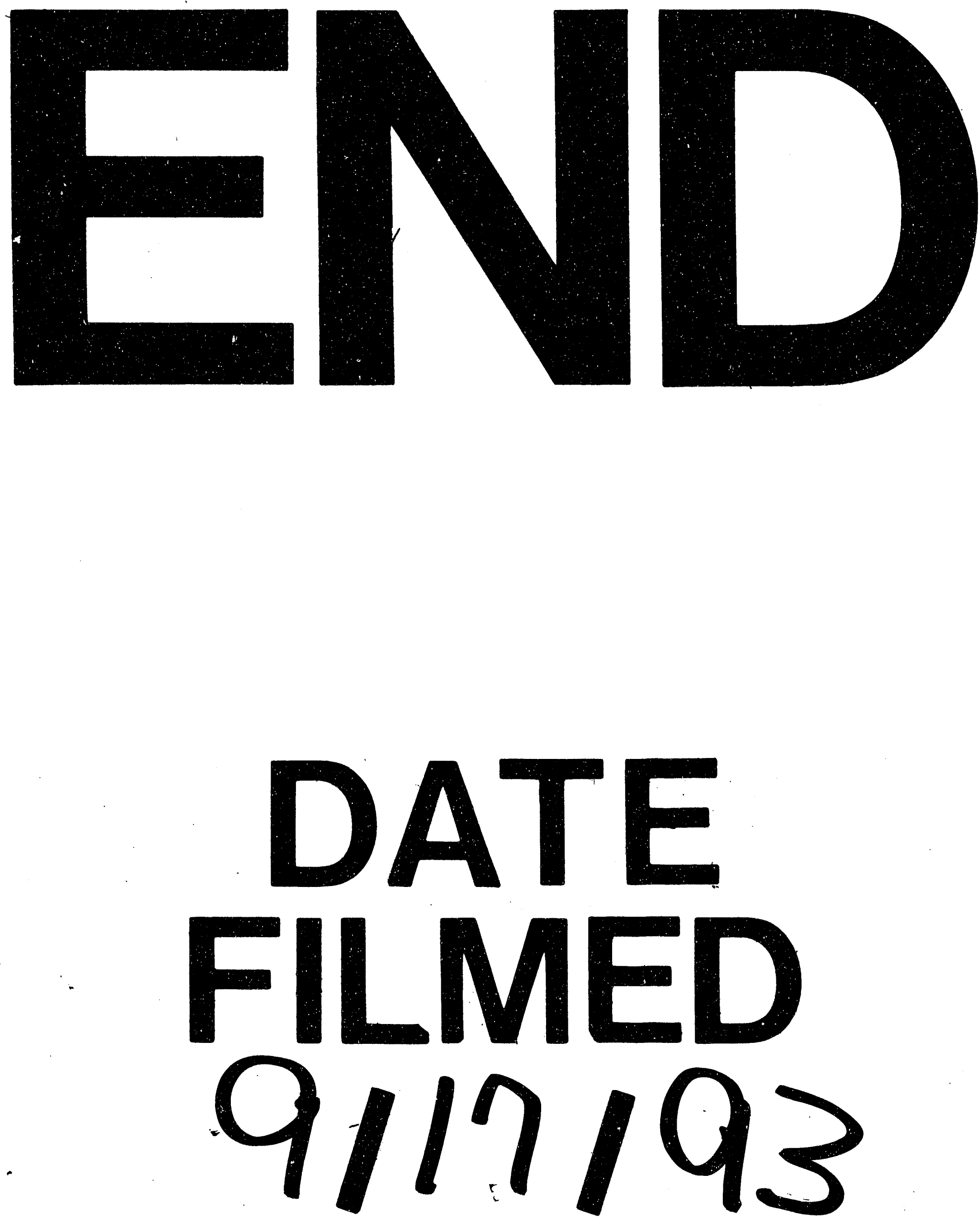
